\title{
O significado do trabalho para os controladores de tráfego aéreo de Curitiba
}

\author{
The meaning of the air traffic controllers work in Curitiba
}

\author{
Arlete Ana Motter ${ }^{[a]}$, Roberto Moraes Cruz ${ }^{[\mathrm{d}]}$, Leila Amaral Gontijo ${ }^{[\mathrm{c}]}$
}

[a] Professora da Universidade Federal do Paraná, Doutora em Engenharia de Produção com ênfase em Ergonomia pela Universidade Federal de Santa Catarina (UFSC), Curitiba, PR - Brasil, e-mail: arlete.motter@uol.com.br

[b] Professor do Departamento de Psicologia da Universidade Federal de Santa Catarina (UFSC), Doutor em Engenharia de Produção pela Universidade Federal de Santa Catarina (UFSC), Florianópolis, SC - Brasil.

[c] Professora do Departamento de Engenharia de Produção da Universidade Federal de Santa Catarina (UFSC), Doutora em Ergonomia na Université de Paris XIII, Florianópolis, SC - Brasil.

\section{Resumo}

O objetivo dos autores foi avaliar o significado do trabalho para os controladores de tráfego aéreo do Segundo Centro Integrado de Defesa Aérea e Controle de Tráfego Aéreo (Cindacta II) de Curitiba, pertencente ao Comando da Aeronáutica - Ministério da Defesa. A pesquisa foi aprovada pelo Comitê de Ética em Pesquisa da Universidade Tuiuti do Paraná, Of. CEP - UTP n. 085/2006. Desenvolveu-se durante o Doutorado em Engenharia de Produção com ênfase em Ergonomia pela UFSC, concluído em 2007. Fizeram parte do estudo 20 militares do sexo masculino, controladores de tráfego aéreo, com idade média de 35 anos e tempo médio de trabalho de 13 anos. Utilizaram-se entrevistas informais e aplicou-se questionário formulado pelos pesquisadores, além de observações gerais da atividade laboral. Os resultados apontam para uma consciência geral dos controladores quanto à responsabilidade que sua tarefa exige e quanto à sua contribuição social e econômica no desenvolvimento da nação. Existe valorização do item rendimento financeiro, que não atendendo à necessidade, leva-os a desempenhar outras atividades de trabalho no contraturno. Os aspectos menos valorizados pelos controladores foram a autoestima e a autorrealização. A satisfação no trabalho pode estar associada ao forte trabalho coletivo e ao fato de que se sentem desafiados a vencer novas dificuldades.

Palavras-chave: Controlador de tráfego aéreo. Trabalho. Significado do trabalho. 


\begin{abstract}
The purpose of this study was to evaluate the meaning of the air traffic controllers of Integrated Center for Air Defense and Air Traffic Control (Cindacta II) of Curitiba, belonging to Aeronautic Command - branch of the Ministry of Defense. This study was approved by the Ethics Committee of Parana University, CEP Of. - UTP n. 085/2006. Developed during a Ph.D. in Production Engineering, whit emphasis on ergonomics UFSC, completed in 2007. Study participants were 20 militaries men, air traffic controllers, with a mean age of 35 years old and with a mean of 13 years experience at Curitiba Center. We used informal interview, questionnaire formulated by the researchers and general observations of work activity. The results indicate a general awareness of drivers about the responsibility that their job requires and how its social and economic contribution in nation building. There is appreciation of the financial income item, which does not meet the need, take them to perform other work activities on the counter-turn. Aspects are less valued by the drivers were self-esteem and self-realization. Job satisfaction may be associated with strong collective work and the fact that they feel challenged to overcome new difficulties.
\end{abstract}

Keywords: Air traffic controller. Work. Work meaning.

\section{Introduçáo}

O significado do trabalho, graças à sua própria subjetividade, é considerado complexo e altamente diferenciado no nível do indivíduo (Bastos, Pinho, Costa, 1995; Borges \& Tamayo, 2001; Cruz, 2003). Reflete uma percepção particularizada e, ao mesmo tempo, uma percepção socialmente construída, sendo a vivência cotidiana dos sujeitos a base sobre a qual constroem suas percepções e conhecimentos sobre o mundo que os cerca (Borges, 2007). O objetivo do estudo foi pesquisar sobre o significado do trabalho para controladores de tráfego aéreo, pois poucos estudos foram realizados com essa população que possui características peculiares por ser, basicamente, militar. Os controladores exercem uma profissão não regulamentada no País e desconhecida do grande público, em que não há espaço para o adágio "errar é humano". Errar significa ser o ator de uma catástrofe. É uma profissão que exige agilidade intelectual, velocidade de raciocínio, uma boa resistência ao estresse e capacidade de adaptação (Moreira \& Vidal, 1999). Nesse sentido envolve um amplo processo cognitivo, em que o homem deve ter conhecimentos específicos, além de ter que lidar com toda uma tecnologia que vem exigindo do homem um redimensionamento de suas relações com a máquina (Pereira, 2001).

Percebe-se, então, a importância em preservar a saúde desses trabalhadores. Com tal intuito, sentiu-se a necessidade de compreender a forma como os indivíduos organizam mentalmente o significado do trabalho, nas diversas facetas que o compõem.
O significado do trabalho, para Patrício (1999), não se refere apenas ao valor monetário, mas também ao prazer do trabalho em si, contribuindo para a qualidade de vida do ser humano. No trabalho, o sujeito se transforma, ao transformar o objeto e vice e versa. Existe um signo que fica - o significado - o qual por sua vez se transforma e é transformado pela ação recíproca do sujeito e/ ou do objeto (Codo, 1997). Nesse sentido, Guérin et al. (2001) entendem que o indivíduo recebe e deixa no objeto a marca do seu próprio trabalho. O resultado da atividade é sempre uma "obra pessoal" daquele que a produziu. Portanto, o significado de sua atividade é fator determinante de sua personalidade e de sua socialização. $\mathrm{O}$ indivíduo dá sentido à vida pelo trabalho. Vários autores (Bastos, Pinho \& Costa, 1995; Codo, 1997; Gaiher Filho \& Melo, 2001) concordam que o trabalho é, fundamentalmente, uma produção social e um dos elementos essenciais na constituição da identidade. No trabalho o sujeito da ação é parte integrante e integrada do fazer, que resulta em sua própria realização (Mendes \& Cruz, 2004).

Assim, Borges e Tamayo (2001) abordam o significado do trabalho como uma cognição subjetiva e social, que possui caráter dinâmico, o que é suficiente para justificar a necessidade de desenvolver estudos nesse campo.

A multidisciplinaridade tem importância para a compreensão de sentidos e significados do trabalho. Trata-se de um construto dinâmico que resulta da interação de variáveis pessoais e ambientais relacionadas ao trabalho (Tolfo \& Piccinini, 2007). 
Para Kanaane (1995, p. 15): “o trabalho é uma ação humanizada, exercida num contexto social que sofre influências oriundas de distintas fontes, o que resulta numa ação recíproca entre o trabalhador e os meios de produção".

Porém, o trabalho mecanicista, com elevada taxa de especialização e automatização, conduz o indivíduo a uma abstração cada vez maior, o qual não se envolve com a tarefa e facilita a substituição do homem pela máquina. Nesse caso, o significado do trabalho torna-se fragmentado, o que faz com que o mesmo se torne estranho para uma parcela das pessoas que o executam, comprometendo sua validade enquanto fonte do equilíbrio humano (Cruz, 2003; Novelli, 2001; Paraguay, 1987; Borges, 2007). O trabalho, fonte de prazer e significação, pode vir a se constituir num preocupante foco de angústia e sofrimento, pela precariedade das condições e pela falta de oportunidades de desenvolvimento profissional (Mendes \& Cruz, 2004).

A compreensão do significado do trabalho compõe-se de muitos aspectos, a bibliografia, entretanto, não é consensual. Um dos primeiros estudos foi da equipe Meaning of Working International Research Team (MOW), nos anos 80, que dividiu o significado do trabalho em três dimensões: a centralidade do trabalho, normas societais e resultados valorizados no trabalho, modelo esse seguido por Bastos, Pinho e Costa (1995) no Brasil. Estudo mais recente, de Borges e Tamayo (2001), propõe um modelo de estrutura cognitiva do significado do trabalho, composto de quatro facetas: centralidade do trabalho, atributos valorativos (o que deve ser), atributos descritivos (o que é) e hierarquia dos atributos. Na centralidade do trabalho há a definição da autoimagem, comprometimento, respostas comportamentais e afetivas ao trabalho. Para Jernigan, Beggs e Kohut (2002), o empregado moralmente comprometido, com forte afetividade positiva, tende a uma aceitação e identificação com os objetivos da empresa. Para a organização, deve-se traduzir numa melhor performance, redução de fadiga, redução de absenteísmo e numa vontade de aceitar maiores responsabilidades.

Fatores pessoais como escolaridade, a natureza da ocupação e setor de trabalho se mostram como variáveis importantes na avaliação do significado do trabalho. Quanto aos produtos valorizados no trabalho, estão ligados à noção de satisfação e motivação. A satisfação no trabalho foi classificada por Dejours
(1987) em concreta e simbólica, sendo a simbólica a que se refere ao significado que a tarefa tem para satisfazer os desejos do trabalhador. O trabalho torna-se fonte de realização e prazer quando vem ao encontro dos significados dos desejos do ser humano e pode, inclusive, ser usado como compensação para suas carências em outros contextos (Grosseman, 2001). Nessa perspectiva, a satisfação no trabalho está relacionada a conteúdos e processos mentais, à moral e ao envolvimento no trabalho, bem como a um estado mental agradável e positivo (Mendes \& Cruz, 2004).

Quanto às normas societais, consistem numa expressão geral do que seriam trocas equitativas entre o que o indivíduo recebe da situação de trabalho e as contribuições que ele traz para o processo de trabalho (Bastos, Pinho \& Costa, 1995). Segundo os autores, as normas societais que colocam o trabalho como direito são mais fortemente introjetadas do que aquelas que enfatizam uma relação de obrigação ou dever do indivíduo para com a sociedade. Portanto, todo trabalhador tem direito a um trabalho digno, interessante, enfim, a um trabalho significante.

Por fim, não se pode falar de saúde dos trabalhadores como se estes constituíssem um grupo homogêneo. Mesmo sendo submetidos a uma mesma cultura organizacional, produzem formas diferenciadas de lidar com essa organização. Formas que variam em função do cargo que ocupam, de todas as representações desses cargos e em função de suas histórias pessoais. O sofrimento mental surge exatamente quando essas histórias são individualmente confrontadas a uma organização do trabalho que as ignora (Gaiher Filho \& Melo, 2001). Portanto, a compreensão dos valores que o ser humano atribui a seu trabalho pode facilitar a elaboração de estratégias para intervenção em prol da promoção de satisfação com o trabalho e sua qualidade de vida, que por sua vez favorecem à instituição na qual ele trabalha (Grosseman, 2001).

\section{Métodos}

O projeto de pesquisa foi submetido e aprovado no Comitê deÉtica em Pesquisa da Universidade Tuiuti do Paraná, sob o número Of. CEP - UTP n. 085/2006. Da totalidade de controladores de tráfego aéreo (60 operadores) do Centro de Controle de Área 
Motter, A. A., Cruz, R. M., \& Gontijo, L. A.

de Curitiba, 20 indivíduos, militares da Força Aérea Brasileira, do sexo masculino, foram pesquisados. Esses operadores apresentavam idade média de 35 anos e tempo médio de atuação de 13 anos.

O contato prévio com os supervisores de equipes possibilitou as entrevistas e observações dos operadores. Os entrevistados foram convidados a participar do estudo e foram informados de que os dados não seriam identificados, mantendo-se, assim, sigilo quanto à autoria das entrevistas. As entrevistas individuais tiveram duração aproximada de 30 minutos e o período de realização foi durante a coleta de dados para a tese de doutorado defendida em 2007, no Programa de Pós-Graduação em Engenharia de Produção da UFSC.

Questionários previamente elaborados pelos autores foram utilizados durante as pausas dos operadores, cuja principal questão era: "qual o significado do trabalho para você?" As respostas, descritivas, foram confrontadas com os resultados da literatura.

As entrevistas e os questionários, em geral, procuraram obter dados sobre as características dos operadores, a organização do trabalho, o ambiente e os níveis de satisfação no trabalho que, juntos, podem facilitar a compreensão do significado do trabalho para essa categoria de trabalhadores.

Durante o período de pesquisa, foram realizadas observações livres dos operadores em sua rotina laboral. Cada operador ocupa o posto de trabalho em um determinado console operacional, sendo responsável por esse respectivo "setor" de controle. A observação ocorreu em dias, turnos e horários variados, com frequência de duas a três vezes por semana, durante cerca de 1 hora em cada visita. Foram feitas visitas, também, aos demais setores que fazem parte do sistema de controle de tráfego aéreo: Controle de Aproximação (APP), meteorologia, sala de Serviço de Informação Aeronáutica (AIS) e a torre de controle do Aeroporto Afonso Pena (São José dos Pinhais, PR), em que as observações livres permitiram conhecer o contexto da situação real do trabalho.

\section{Caracterização do trabalho do controlador de tráfego aéreo}

O controlador de tráfego aéreo é o encarregado pela prestação de serviços a quem esteja voando ou que se proponha a voar, fornecendo informações de voo às aeronaves, informações meteorológicas, o acionar de alertas e, também, fazendo a ordenação do fluxo de tráfego aéreo entre os diferentes aeroportos. Ele supervisiona uma zona do espaço aéreo denominada "setor". O espaço aéreo é cortado por diferentes aerovias, pelas quais as aeronaves se deslocam de um aeroporto a outro. Para todas essas rotas existem regras específicas de navegação, que devem ser instruídas pelo controlador de tráfego aéreo, garantindo a separação mínima entre os aviões. O Centro de Controle de Área de Curitiba coordena cerca de 1.800 planos de voo por dia. Voos comerciais e militares, nacionais e internacionais, evoluindo nos Estados da região sul do Brasil (Motter, 2007).

O controle de tráfego aéreo é considerado tarefa cognitiva complexa, pois existem restrições e demandas cognitivas colocadas aos operadores (Marmaras \& Pavard, 1999). Os fatores que contribuirão para o aumento da complexidade cognitiva da tarefa são: natureza dinâmica do ambiente, número importante de partes interconectadas, incerteza de dados e riscos associados às consequências de uma decisão imprópria (Salembier \& Pavard, 2004).

As soluções são tomadas de acordo com as características contextuais, que estão em constantes mudanças (número de aeronaves, tipo das aeronaves, combustível remanescente, entre outros), segundo Pavard e Dugdale (2006).

\section{Resultados e discussão}

O controlador de tráfego aéreo, do Centro de Controle de Área de Curitiba, além do serviço operacional, também concorre a escalas militares que coincidem com suas folgas, o que compromete seu descanso, resultando em uma das principais queixas dos entrevistados. As escalas operacionais e militares ficam "apertadas" por causa do contingente reduzido de operadores (Motter, Tokars \& Gontijo, 2003; Motter, 2007). Os turnos de trabalho são alternados (três dias de trabalho seguido de dois dias de folga) o que, segundo a literatura, pode causar alterações sono/vigília, alterações gastrointestinais, distúrbios psicológicos e problemas familiares e sociais (Itani, 1999; Iida, 1998; Jordano, Sob, Barbosa, Lima Silva \& Souza, 1989).

Soma-se, ainda, a característica da própria organização militar que se reveste de autoridade, força e poder, dá margem para pouca flexibilidade 
e maximiza a hierarquia, porque sua própria missão assim o exige. A adaptação ao trabalho representa a adesão do controlador não apenas às condições de trabalho propriamente ditas, mas também aos valores morais e à ideologia militar. Manter a qualidade da relação motivação/satisfação e o prazer proveniente do conteúdo significativo e simbólico do trabalho faz-se também necessário (Dejours, 1987).

O controlador tem a respeito de si mesmo, segundo Nocera (2003), graças à atividade profissional que desempenha, a ideia de ser uma espécie de “super-homem". Detém, em suas mãos, considerável poder; a vida de muitas pessoas depende diretamente dele, não lhe sendo permitido falhar. A autora cita que condição semelhante a essa foi identificada por Dejours (1987) entre os pilotos de caça, um sistema defensivo que chamou de "ideologia da profissão", uma verdadeira necessidade para manter um moral feito de orgulho, de insolência e de agressividade. Cada uma dessas características é indispensável para enfrentar as condições de trabalho e também foram encontradas nesta pesquisa entre os operadores entrevistados.

Os controladores deste estudo relataram que a família não está satisfeita com o número de horas que dedicam a ela semanalmente. $\mathrm{Na}$ centralidade do trabalho, avaliado por Bastos, Pinho e Costa (1995) na Bahia, e no estudo internacional da MOW, a família, o trabalho e o lazer foram esferas de maior importância, e podem se tornar fonte de conflitos entre si. As relações conflituosas geralmente decorrem entre a história do indivíduo e a história da sociedade (Wisner, 1994). Cada indivíduo chega no seu local de trabalho com seu capital genético, a sua história antes do nascimento, as suas marcas acumuladas durante a vida, seus costumes pessoais e seus aprendizados. Tudo isso irá pesar no custo pessoal da situação de trabalho, pois isso confere a cada indivíduo características únicas e pessoais (por exemplo, Dejours, 1994; Cruz, 2003; Wisner, 1994).

Em geral, os operadores de Curitiba, se dizem apaixonados pelo que fazem, apesar da insatisfação quanto à remuneração. O controlador, apesar de toda exigência e responsabilidade que lhe é dirigida, recebe o mesmo salário e tratamento dispensados ao técnico administrativo. Essa situação produz, no mínimo, descontentamento entre os trabalhadores. Portanto, fazem "bicos" para complementar a renda, criando uma sobrecarga de atividades muito comprometedora para quem deve manter atenção constante no radar. Moreira e Vidal (1999) defendem a ideia de que os controladores deveriam atuar como civis, uma vez que a graduação que possuem os que são militares lhes impede de perceber um salário adequado, sem que se instale um incoerente desequilíbrio entre remunerações nas fileiras castrenses. Dejours (1987) relaciona o salário com numerosos significados: concretos (sustentar a família, ganhar as férias, etc.), mas também abstratos, na medida em que contém sonhos, fantasias e projetos. Ou o inverso, em que o salário pode veicular todas as significações negativas que implicam as limitações materiais que ele impõe.

Averiguou-se que $80 \%$ dos operadores do estudo possuem nível superior ou o estão cursando (Motter, Tokars \& Gontijo, 2003). Tal fato é justificado como forma de complementar a renda familiar e garantir atividade laboral, pois como militares se aposentam jovens. Segundo Grosseman(2001), Motter eMichels (2004), a dificuldade de manter-se atualizado torna-se um fator limitante na busca da satisfação.

A profissão de controlador de tráfego aéreo confere certo status, tanto que nessa função dá comandos a militares hierarquicamente superiores: os pilotos de aeronaves. Nesse sentido, encontram prazer, por meio do poder que possuem, ao estar no comando em seu console. Sua satisfação advém da autonomia para a tomada de decisão. Ou seja, possuem margem de manobra para realizar seu trabalho. Status e prestígio foram os produtos menos valorizados no trabalho no estudo de Bastos, Pinho e Costa (1995), entretanto, para Dejours (1987), tanto mais honroso se a tarefa é complexa, tanto mais admirada pelos outros se ela exige conhecimento, responsabilidade e riscos. Segundo Nocera (2003), quanto mais complexo mais o homem sente crescer sua valorização em termos laborativos, uma vez que essa tecnologia não o aliena, mas vem em seu auxílio para permitir o controle cada vez mais seguro do tráfego.

Em resposta à pergunta: "qual o significado do trabalho para você?", o item mais apontado foi o tráfego aéreo como uma forma de servirà sociedade, de contribuir para o desenvolvimento do País. Em segundo lugar, o trabalho como forma de garantir o sustento. Aspectos menos valorizados foram o trabalho como forma de elevar a autoestima e a realização pessoal, a responsabilidade por envolver vidas e o comprometimento com a segurança das operações. 
Motter, A. A., Cruz, R. M., \& Gontijo, L. A.

Realização pessoal e rendimentos necessários foram os elementos mais valorizados no trabalho, no estudo de Bastos et al. (1995), sendo esse último o mais valorizado em todos os países (MOW), principalmente Japão e Alemanha. Infelizmente a desigualdade social faz com que muitos trabalhadores brasileiros lutem pela sobrevivência, ou seja, na Escala de Maslow, citada, por exemplo, por Coury (1999) e Rodrigues (1999), esses indivíduos estariam no primeiro nível, uma vez que as necessidades mais primárias seriam as fisiológicas, seguidas pelas de segurança, contato social, autoestima, ser estimado pelos outros e autoatualização.

$\mathrm{Na}$ motivação para o trabalho do controlador de tráfego aéreo, o bom relacionamento entre os colegas de trabalho contribui positivamente, pois demonstram que há camaradagem entre os subordinados, pares e superiores. Regularmente se reúnem fora do ambiente de trabalho para futebol ou atividades de lazer. Nesse caso, o trabalho funciona como fonte de satisfação por meio das relações sociais. Entretanto, revelam descontentamento quanto às chefias de equipes de trabalho, ou seja, chefia considerada despreparada e ausência de comando eficiente no setor. Quanto à valorização no trabalho pela instituição, a Força Aérea Brasileira oferece oportunidade de crescimento profissional limitada, pois o sistema de promoção não possibilita ascensão até o oficialato, como controlador de tráfego aéreo, sem a prestação de concorrido concurso interno. Na hierarquia militar, como controladores, alcançam naturalmente a graduação máxima de suboficial, impossibilitando melhor remuneração.

A compreensão dos padrões de significado do trabalho para o controlador de tráfego aéreo chama a atenção no sentido de políticas capazes de atingir diferencialmente os trabalhadores.

\section{Conclusóes}

O estudo possibilitou conhecer o significado do trabalho para os controladores de tráfego aéreo do Centro de Controle de Área de Curitiba, o qual contempla aspectos positivos e negativos. Houve predomínio do trabalho como forma de servir à sociedade e contribuir com o desenvolvimento da nação, seguido da valorização da remuneração, assemelhando-se a outros estudos, em detrimento da autoestima e autorrealização. Certamente futuras pesquisas sobre o tema, significado do trabalho, deverão surgir, pois este é um assunto cuja bibliografia é escassa e que possui caráter dinâmico.

O tema "significado do trabalho para os controladores de tráfego aéreo" destaca-se, dada a importância dessa profissão para a sociedade. Nesse caso, a relação homem/organização/trabalho gera amplas repercussões, cujas consequências indesejadas colocam em risco muitas vidas. Por outro lado, conhecendo-se a dimensão psíquica do trabalho, a qual envolve elementos psicológicos como: motivação, afetividade, angústia, insegurança, entre outras, pode-se evitar descompensações nas condições de saúde dos trabalhadores e, consequentemente, maior segurança no tráfego aéreo.

\section{Referências}

Bastos, A. V. B., Pinho, A. P. M., \& Costa, C. A. (1995). Significado do trabalho: Um estudo entre trabalhadores inseridos em organizações formais. Revista de Administração de Empresas, 35(6), 20-29.

Borges, L. O., \& Tamayo, A. (2001). A estrutura cognitiva do significado do trabalho. Revista Psicologia: Organizações e Trabalho, 1(2), 11-44.

Borges, Z. (2007). O significado do trabalho: Uma reflexão sobre a institucionalização do trabalho na empresa integrada e flexível. Gesta, 3(1), 121-143.

Codo, W. (1997). Um diagnóstico do trabalho em busca do prazer. In A. Tamoyo. Trabalho, organizações e cultura (pp. 21-40). São Paulo: Autores Associados.

Coury, H. J. C. G. (1999). Satisfação no trabalho e satisfação na vida: questões teóricas e metodológicas. In A. L. Neri. (Org.). qualidade de vida e idade madura (pp. 137-156). Campinas: Papirus.

Cruz, R. M. (2003). Psicologia ergonômica? Florianópolis: UFSC. Apostila utilizada na disciplina de Psicologia do Programa de Pós-Graduação em Engenharia de Produção - UFSC.

Dejours, C. (1987). A loucura do trabalho. São Paulo: Oboré.

Dejours, C. (1994). Psicodinâmica do trabalho. São Paulo: Atlas. 
Gaigher Filho, W., \& Lopes Melo, S. I. (2001). LER/ DORT: A psicossomatização no processo de surgimento e agravamento. São Paulo: LTR.

Guérin, F., Laville, A., Daniellou, F., Duraffourg, J., \& Kerguelen, A. (2001). Compreender o trabalho para transformá-lo: A prática da ergonomia. São Paulo: Edgard Blucher.

Grosseman, S. (2001). Satisfação com o trabalho: Do desejo à realidade de ser médico. Tese de Doutorado, Programa de Pós-Graduação em Engenharia de Produção da Universidade Federal de Santa Catarina, Florianópolis.

Iida, I. (2005). Ergonomia: Projeto e produção. São Paulo: Edgard Blucher.

Itani, A. (1999). Tecnologia da informação e os riscos do trabalho na aviação. São Paulo: Universidade Estadual Paulista.

Jernigan, I. E., III, Beggs, J. M., \& Kohut, G. F. (2002). Dimensions of work satisfaction as predictors of commitment type. Journal of Managerial Psychology, 17(7), 564-579.

Jordano, A. F., Sob, F. C., Barbosa, J. A., Lima Silva, L., \& Souza, R. F. (1989). Efeitos do trabalho em rodízio ininterrupto sobre a saúde de operadores de estações elétricas. Anais do $4^{\circ}$ Seminário Brasileiro de Ergonomia. Rio de Janeiro: Abergo.

Kanaane, R. (1995). Comportamento humano nas organizações: $\mathbf{O}$ homem rumo ao século XXI. São Paulo: Atlas.

Marmaras, N., Pavard, B. (1999). Abordagem orientada ao problema para o projeto de sistemas de tecnologia da informação para o auxílio às tarefas cognitivas complexas. (M. C. P. L. Zamberlan, Trad.). Recuperado em 20 dez. 2009, em http:// www.ergonomia.com.br/htm/Marmarastextos.htm

Mendes. A. M., \& Cruz, R. M. (2004). Trabalho e saúde no contexto organizacional: vicissitudes teóricas. In A. Tamayo. (Org.). Cultura e saúde nas organizações (pp. 39-58). Porto Alegre: Artmed.

Moreira, S. B., \& Vidal, M. C. (1999). Relatórios de pesquisas ergonômicas realizadas no Controle de Tráfego Aéreo do Rio de Janeiro (APP/RJ). Rio de Janeiro: APP/RJ.
Motter, A. A., Tokars, E., \& Gontijo, L. A. (2003). Análise ergonômica do trabalho dos controladores de tráfego aéreo do Centro de Controle de Área de Curitiba. Anais do XXIII Encontro Nacional de Engenharia de Produção - ENEGEP. Ouro Preto: Autor.

Motter, A. A., \& Michels, G. (2004). Qualidade de vida dos médicos militares do Hospital Geral de Curitiba. Revista Fisioterapia Brasil, 5(3), 177-182.

Motter, A. A. (2007). Análise da carga de trabalho em sistemas complexos: Gestão da variabilidade e imprevisibilidade nas atividades do controlador de tráfego aéreo. Tese Doutorado em Engenharia de Produção, Universidade Federal de Santa Catarina, Florianópolis.

Nocera, C. (2003). O homem do sofá: Representação da crise de identidade vivida no mundo do trabalho. Monografia do Curso de Pós-Graduação em Psicologia do Trabalho da Universidade Federal do Paraná, Curitiba, Paraná.

Novelli, A. L.C. R. (2001).Aquestãohumana: Reflexões sobre a fala e o trabalho. Recuperado em 5 ago. 2001, em www.intercom.org.br/gtco/novelli.htm.

Oliveira, J. C. (2001). Compreensão e equívocos. Revista Proteção, 14(114), 53.

Patrício, Z. M., Casagrande, J. L., \& Araújo, M. F. (1999). Qualidade de vida do trabalhador: Uma abordagem qualitativa do ser humano através de novos paradigmas. Florianópolis: Do autor.

Paraguay, A. I. B. B. (1987). Ergonomia. Carga de trabalho. Fadiga mental. Revista Brasileira de Saúde Ocupacional, 15(59), 39-43.

Pavard, B., \& Dugdale, J. (2006). The contribution of complexity theory to the study of socio-technical cooperative systems. Toulouse, France: Université Paul Sabatier.

Pereira, M. C. (2001). Aspectos psicológicos no controle de tráfego aéreo e o controlador de tráfego aéreo: Elaborações de uma prática em construção. In M. C. Pereira \& S. L. O. Ribeiro. (Org.). Os vôos da psicologia no Brasil: Estudos e práticas na aviação. (pp. 39-46). Rio de Janeiro: NuICAF.

Rodrigues, M. V. C. (1999). Qualidade de vida no trabalho. Petrópolis: Vozes. 
Salembier, P., \& Pavard, B. (2004). Analyse et modélisation des activités coopératives situées. Evolution d'un questionnement et apports à la conception. Activités, 1(1), 87-99. Recuperado em 21 dez. 2009, em http:/ / www.activites.org/v1n1/salembier.pdf

Tolfo, S. R., \& Piccinini, V. (2007). Sentidos e significados do trabalho: explorando conceitos, variáveis e estudos empíricos brasileiros. Revista Psicologia \& Sociedade, 19(1), 31-46.

Wisner, A. (1994). A inteligência no trabalho. São Paulo: Fundacentro/Unesp. Textos selecionados de ergonomia.

Recebido: 31/01/2010

Received: 01/31/2010

Aprovado: 30/06/2010

Approved: 06/30/2010 